Jurnal Tanah dan Air (Soil and Water Journal)

ISSN: 1411-5719(p): 2655-500X (e), Volume 17 Nomor 1 (Juni 2020): 20 - 25 (http://jurnal.upnyk.ac.id/index.php/ita/index)

\title{
PENGARUH BAHAN ORGANIK DAN TANAH VERTISOL SEBAGAI PEMBENAH TANAH TERHADAP KETERSEDIAAN DAN PELINDIAN KALIUM DI TANAH REGOSOL PASIR PANTAI
}

\section{(EFFECTS OF ORGANIC MATERIALS AND VERTISOL AS SOIL CONDITIONER FOR THE AVAILABILITY AND LEACHING OF POTASSIUM IN COASTAL REGOSOL)}

\author{
Tedi Kurnia Putra ${ }^{1)}$, Miseri Roeslan Afany ${ }^{2 *)}$, R Agus Widodo ${ }^{2)}$ \\ ${ }^{1)}$ Prodi Agroteknologi, Universitas Pembangunan Nasional Veteran Yogyakarta \\ ${ }^{2}$ Prodi Ilmu Tanah, Universitas Pembangunan Nasional Veteran Yogyakarta \\ ${ }^{*}$ Corresponding author E - mail: miseriroeslan.afany@ yahoo.com
}

\begin{abstract}
Coastal regosol can be an alternative land in agricultural development, particularly in the coastal areas. However, the main obstacle to utilize coastal regosol for agriculture is sand-textured soil with a loose structure. Moreover, the low cation exchange capacity (CEC) value makes it difficult for the soil to store nutrients needed by plants in large quantities such as Potassium (K). One of the efforts to improve the properties of coastal regosol is the application of soil conditioner. In this current research, the applied soil conditioners were cow manure and Vertisol. This research aims to identify the effect of cow manure and Vertisol as soil conditioners on the availability and leaching of Potassium (K) as well as chemical properties of coastal regosol. It applied a completely randomized 3 -factor design. The first factor was cow manure with 3 levels $(0,20$, and 30 tons/ha). The second factor was vertisol with 3 levels $(0,20$, and 30 tons/ha). This research was conducted in a greenhouse with an incubation period of 30 days. The data were analyzed with ANOVA at a 5\% significance level followed by the DMRT (Duncan's Multiple Range Test) of a 5\% level. The results showed that the application of cow manure significantly affected the parameters of K-available soil, K-leached, soil pH, C-organic soil, and Cation Exchange Capacity (CEC). The use of vertisol also significantly affected the parameters of K-available soil, K-leached, soil pH, C-organic soil, and cation exchange capacity (CEC). Cow manure provided a better result than vertisol soil and its best dosage was 30 tons/ha.
\end{abstract}

Keywords: potassium, cow manure, vertisols, coastal regosols.

\begin{abstract}
ABSTRAK
Regosol pasir pantai dapat menjadi lahan alternatif dalam pengembangan pertanian terutama di wilayah pesisir. Namun, kendala utama pada lahan pasir pantai untuk pertanian adalah sifat tanah yang bertekstur pasir dengan struktur yang lepas. Selain itu nilai Kapasitas Pertukaran Kation (KPK) yang rendah juga menyebabkan tanah ini sulit untuk menyimpan hara yang dibutuhkan oleh tanaman dalam jumlah banyak seperti Kalium (K). Salah satu upaya dalam memperbaiki sifat Regosol pasir pantai adalah dengan penambahan pembenah tanah. Pembenah tanah yang digunakan pada penelitian ini adalah pupuk kandang sapi dan tanah Vertisol. Penelitian ini bertujuan untuk mengetahui pengaruh pupuk kandang sapi dan tanah Vertisol
\end{abstract}


sebagai pembenah tanah terhadap ketersediaan dan pelindian Kalium (K) serta terhadap beberapa sifat kimia tanah Regosol pasir pantai. Rancangan yang digunakan adalah Rancangan Acak Lengkap (RAL) Faktorial 3 ulangan, faktor pertama adalah pupuk kandang sapi dengan 3 aras (dosis 0 ton/ha, 20 ton/ha, dan 30 ton/ha), dan faktor yang kedua adalah tanah Vertisol dengan 3 aras (dosis 0 ton/ha, 20 ton/ha, dan 30 ton/ha). Penelitian ini dilakukan di rumah kaca dengan waktu inkubasi selama 30 hari. Data hasil penelitian dianalisis dengan ANOVA pada jenjang nyata 5\% dilanjutkan dengan uji DMRT (Duncan's Multiple Range Test) pada jenjang 5\%. Hasil Penelitian menunjukkan penambahan pupuk kandang sapi berpengaruh nyata terhadap parameter K-tersedia tanah, K-terlindi, pH tanah, C-organik tanah, dan Kapasitas Pertukaran Kation (KPK). Penambahan tanah Vertisol juga berpengaruh nyata terhadap parameter K-tersedia tanah, K-terlindi, $\mathrm{pH}$ tanah, C-organik tanah, dan Kapasitas Pertukaran kation (KPK). Pemberian pupuk kandang sapi memberikan hasil yang lebih baik dibanding tanah vertisol, dengan dosis pemberian terbaik sebesar 30 ton/ha.

Kata kunci: Kalium, pupuk kandang sapi, Tanah Vertisol, Regosol pasir pantai.

\section{PENDAHULUAN}

Ketersediaan lahan pertanian yang semakin berkurang akibat alih fungsi lahan mengharuskan pelaku pertanian mencari alternatif pengganti lahan pertanian. Salah satu upaya yang dapat mengatasi permasalahan ini adalah dengan menggunakan lahan alternatif seperti lahan pasir pantai. Keberadaan lahan pasir pantai yang ada di daerah pesisir Daerah Istimewa Yogyakarta diyakini mampu untuk mengatasi permasalahan lahan pertanian yang semakin menyempit jika dapat dimanfaatkan dengan cara yang baik dan benar.

Tanah di lahan pasir mempunyai kesuburan yang kurang baik karena bertekstur pasir, struktur butir tunggal sampai kersai, konsistensi lepas-lepas sehingga mempunyai kemampuan meloloskan air yang tinggi. Sifat kimia tanah pasir pantai juga kurang menguntungkan bagi pertumbuhan tanaman. Tanah ini memiliki KPK dan kandungan hara yang rendah, karena kandungan mineralnya belum terlapukkan dan adanya pelindian. Oleh karena itu, perlu adanya penggunaan pembenah tanah di lahan pasir pantai yang diharapkan dapat mengurangi terjadinya pencucian hara, salah satunya hara Kalium (K) yang dibutuhkan tanaman dalam jumlah yang besar. Salah satu sumber Kalium (K) yang dapat diberikan adalah dengan penambahan pupuk $\mathrm{KCl}$. Dengan tersedianya Kalium $(\mathrm{K})$ yang bersumber dari pupuk tersebut pada tanah diharapkan dapat memacu dan meningkatkan produktivitas tanaman yang dibudidayakan di lahan pasir pantai.

\section{BAHAN DAN METODE}

Penelitian dilaksanakan di Rumah Kaca Fakultas Pertanian UPN "Veteran" Yogyakarta. Analisis pendahuluan dan setelah perlakuan dilakukan di Laboratorium Kimia Tanah Fakultas Pertanian UPN "Veteran" Yogyakarta. Bahan yang digunakan dalam penelitian diantaranya yaitu tanah Regosol pasir pantai, tanah Vertisol, pupuk kandang sapi, pupuk KCI, aquades, dan kemikalia. Alat yang digunakan yaitu cangkul, cetok, karung, paralon diameter $9 \mathrm{~cm}$, tutup paralon, saringan, timbangan, corong, kerangka alat percobaan, dan alat-alat untuk analisis di laboratorium. Penelitian ini 
dilaksanakan dengan menggunakan metode percobaan 2 faktor yang disusun dalam Rancangan Acak Lengkap (RAL). Setiap faktor terdiri dari 3 aras, dan setiap perlakuan diulang sebanyak 3 kali, sehingga terdapat 27 unit percobaan. Inkubasi dilakukan selama 30 hari.

\section{HASIL DAN PEMBAHASAN}

Berdasarkan hasil analisis sidik ragam menunjukkan tidak terdapat interaksi antara perlakuan pupuk kandang sapi dan tanah Vertisol pada parameter $\mathrm{pH}$ tanah, Corganik tanah, Kapasitas Pertukaran Kation (KPK), K-tersedia, dan K-terlindi.

Tabel 1. Rerata nilai Kapasitas Pertukaran Kation (KPK) tanah pada aplikasi pupuk kandang sapi dan tanah Vertisol $(\mathrm{cmol}(+) / \mathrm{kg})$.

\begin{tabular}{ccccc}
\hline Perlakuan & \multicolumn{4}{c}{ Pupuk Kandang Sapi } \\
\hline Vertisols & 0 ton/ha $(\mathbf{P 0})$ & $\mathbf{2 0}$ ton/ha $(\mathbf{P 1})$ & 30 ton/ha $(\mathbf{P 2})$ & Rerata \\
\hline 0 ton/ha $($ V0) & 1,69 & 1,78 & 1,6 & $1,74 \mathrm{p}$ \\
$\mathbf{2 0}$ ton/ha $(\mathbf{V 1})$ & 1,73 & 1,80 & 1,87 & $1,80 \mathrm{q}$ \\
$\mathbf{3 0}$ ton/ha $($ V2) & 1,78 & 1,80 & 1,92 & $1,83 \mathrm{q}$ \\
\hline Rerata & $1,73 \mathrm{a}$ & $1,79 \mathrm{~b}$ & $1,85 \mathrm{c}$ & $(-)$ \\
\hline
\end{tabular}

Keterangan: Angka-angka yang diikuti huruf yang sama pada kolom $(a, b, c)$ atau baris $(\mathrm{p}, \mathrm{q}, \mathrm{r})$ menunjukan tidak ada beda nyata menurut Uji Jarak Berganda Duncan pada jenjang nyata 5\%. (-): Tidak ada interaksi

Hasil uji DMRT pada parameter KPK tanah menunjukkan pengaruh nyata pada masing-masing pemberian pupuk kandang sapi dan tanah Vertsiol. Hasil analisis data menunjukkan bahwa pemberian pupuk kandang sapi dan tanah Vertisol sejalan dengan peningkatan nilai Kapasitas Pertukaran Kation (KPK) tanah, seperti yang dapat dilihat pada tabel 1. Perlakuan pemberian pupuk kandang sapi dosis 30 ton/ha (P2) memberikan hasil tertinggi dengan nilai KPK sebesar $1.85 \mathrm{cmol}(+) / \mathrm{kg}$. Hal ini sejalan dengan hasil penelitian Wigati, et al., (2006) bahwa penambahan pupuk kandang dapat meningkatkan nilai Kapasitas Pertukaran Kation (KPK) tanah pasir pantai. Hal ini dikarenakan pupuk kandang merupakan sumber koloid organik bagi tanah yang mengandung muatan negatif sehingga proses pertukaran kation yang terjadi dalam tanah lebih tinggi, selain itu proses dekomposisi yang menghasilkan humus juga menjadi penyebab terjadinya peningkatan nilai KPK tanah.

Peningkatan nilai KPK akibat penambahan tanah Vertisol dikarenakan pada tanah Vertisol terdapat banyak muatan negatif yang dapat meningkatkan proses pertukaran kation dalam tanah, selain itu nilai KPK tanah Vertisol yang digunakan juga tergolong tinggi yaitu sebesar $26,43 \mathrm{cmol}(+) / \mathrm{kg}$. Menurut Nuryamsi, et al. (2005), tanah Vertisol umumnya memiliki jenis mineral lempung smektit yang memiliki kadar lempung lebih dari $>30 \%$ serta nilai KPK yang tinggi, dikarenakan adanya substitusi isomorfik $\mathrm{Al}^{3+}$ terhadap $\mathrm{Si}^{4+}$ pada lempeng Si-tetrahedron, proses ini menjadi sumber muatan negatif permanen pada tanah Vertisol, karena tidak berubah dengan berubahnya pH tanah. Hasil analisis data menunjukkan bahwa pemberian pupuk kandang sapi dan tanah Vertisol sebagai pembenah tanah berpengaruh nyata terhadap kenaikan nilai Ktersedia tanah, seperti yang dapat dilihat pada tabel 2. Perlakuan pemberian tanah Vertisol yang dapat meningkatkan K-tersedia dalam tanah dikarenakan tanah Vertisol berasal dari batuan induk lempung berkapur yang didominasi oleh asosiasi labradorit, 
lapukan mineral, hornblende hijau, hiperstin, dan kuarsa dan terdapat pengkayaan dari bahan volkan intermedier, yang menyebabkan K total tanah Vertisol tinggi (LPT, 1979). Selain itu disebabkan pula tanah Vertisol memiliki mineral lempung jenis smektit yang dapat menjerap dan mempertukarkan $\mathrm{K}+$ dalam jerapan tanah secara aktif sehingga menjaga ketersediaan K dalam tanah (Prasetyo, 2005).

Tabel 2. Rerata nilai K-tersedia tanah pada aplikasi pupuk kandang sapi dan tanah Vertisol (ppm)

\begin{tabular}{ccccc}
\hline Perlakuan & \multicolumn{4}{c}{ Pupuk Kandang Sapi } \\
\hline Vertisols & 0 ton/ha $(\mathbf{P 0})$ & 20 ton/ha $(\mathbf{P 1})$ & $\mathbf{3 0}$ ton/ha $(\mathbf{P 2})$ & Rerata \\
\hline 0 ton/ha $(\mathbf{V 0})$ & 65,11 & 71,63 & 84,67 & $73,80 \mathrm{p}$ \\
20 ton/ha $(V 1)$ & 71,64 & 91,19 & 91,19 & $84,67 \mathrm{q}$ \\
30 ton/ha $($ V2) & 78,17 & 91,20 & 97,74 & $89,04 \mathrm{q}$ \\
\hline Rerata & $71,64 \mathrm{a}$ & $84,68 \mathrm{~b}$ & $91,20 \mathrm{~b}$ & $(-)$ \\
\hline
\end{tabular}

Keterangan: Angka-angka yang diikuti huruf yang sama pada kolom (a,b,c) atau baris (p,q,r) menunjukan tidak ada beda nyata menurut Uji Jarak Berganda Duncan pada jenjang nyata 5\%. (-): Tidak ada interaksi

Peningkatan nilai K-tersedia tertinggi terdapat pada dosis P2 (30 ton/ha) sebesar 91.20 ppm, dikarenakan pada pupuk kandang sapi juga terdapat banyak muatan negatif yang bersumber dari koloid organik sehingga lebih dapat menjerap $\mathrm{K}+$ yang ada dalam larutan tanah. Pupuk kandang sapi juga merupakan sumber K-tersedia yang cukup baik bagi tanah, ketersediaan $\mathrm{K}$ oleh pupuk kandang sapi dikarenakan proses dekomposisi yang menghasilkan mineralisasi bahan organik sehingga unsur hara terlepas dari bahan organik dan tersedia bagi tanah (Margolang, et al., 2015).

Tabel 3. Rerata jumlah K-terlindi pada aplikasi pupuk kandang sapi dan tanah Vertisol (mg).

\begin{tabular}{ccccc}
\hline Perlakuan & \multicolumn{4}{c}{ Pupuk Kandang Sapi } \\
\hline Vertisols & 0 ton/ha (P0) & 20 ton/ha (P1) & 30 ton/ha (P2) & Rerata \\
\hline 0 ton/ha $(V 0)$ & 11,49 & 9,72 & 8,84 & $10,02 \mathrm{p}$ \\
$\mathbf{2 0}$ ton/ha $(V 1)$ & 10,36 & 8,82 & 5,26 & $8,15 \mathrm{q}$ \\
$\mathbf{3 0}$ ton/ha (V2) & 10,06 & 6,66 & 5,07 & $7,27 \mathrm{q}$ \\
\hline Rerata & $10,64 \mathrm{a}$ & $8,40 \mathrm{~b}$ & $6,39 \mathrm{~b}$ & $(-)$ \\
\hline
\end{tabular}

Keterangan: Angka-angka yang diikuti huruf yang sama pada kolom (a,b,c) atau baris (p,q,r) menunjukan tidak ada beda nyata menurut Uji Jarak Berganda Duncan pada jenjang nyata $5 \%,(-)$ : Tidak ada interaksi

Hasil analisis data menunjukkan bahwa pemberian pupuk kandang sapi dan tanah Vertisol sebagai pembenah tanah berpengaruh nyata terhadap penurunan jumlah K-terlindi, seperti yang dapat dilihat pada tabel 3. Menurut Rajiman, et al. (2014) bahwa penambahan pembenah tanah seperti pupuk kandang dan tanah lempung dapat meningkatkan niali Kapasitas Pertukaran Kation (KPK) di tanah pasir pantai. Hal ini berdampak terhadap kemampuan tanah dalam menjerap unsur hara, $\mathrm{K}+$ yang ada pada larutan tanah akan dapat dijerap atau dipertukarkan, sehingga dapat terhindar dari proses pelindian. 
Hasil analisis juga menunjukkan bahwa perlakuan pupuk kandang sapi dengan dosis P2 (30 ton/ha) lebih dapat menurunkan jumlah pelindian Kalium dibandingkan dengan perlakuan lainnya dengan jumlah K-terlindi sebesar 6,39 mg (Tabel 3). Hal ini dikarenakan pupuk kandang sapi dapat menghasilkan humus yang mempunyai luas permukaan dan kemampuan absorpsi yang lebih besar dari lempung, serta dapat meningkatkan kemampuan tanah dalam menjerap dan mempertukarkan kation $\mathrm{K}+$ dalam tanah, sehingga jumlah pelindian Kalium dalam tanah mengalami penurunan.

Peningkatan jumlah K-tersedia dalam tanah sejalan dengan penurunan jumlah Kterlindi, hal ini dibuktikan dengan uji korelasi parameter K-tersedia tanah terhadap parameter K-terlindi yang menghasilkan nilai $\mathrm{r}$ sebesar $-0,917$ yang menunjukkan korelasi negatif dan berpengaruh kuat. Hal ini dikarenakan pengaruh pupuk kandang sapi dan tanah vertisol yang ditambahkan dapat meningkatkan nilai Kapasitas Pertukaran Kation (KPK) tanah sehingga kalium yang berada dalam larutan tanah akan dapat terjerap dan terhindar dari pelindian (leaching).

Tabel 4. Rerata kadar C-organik tanah pada aplikasi pupuk kandang sapi dan tanah Vertisol (\%).

\begin{tabular}{ccccc}
\hline Perlakuan & \multicolumn{4}{c}{ Pupuk Kandang Sapi } \\
\hline Vertisols & 0 ton/ha $(\mathbf{P 0})$ & $\mathbf{2 0}$ ton/ha $(\mathbf{P 1})$ & $\mathbf{3 0}$ ton/ha $(\mathbf{P 2})$ & Rerata \\
\hline 0 ton/ha $($ V0) & 0,26 & 0,32 & 0,36 & $0,31 \mathrm{p}$ \\
$\mathbf{2 0}$ ton/ha $($ V1) & 0,30 & 0,34 & 0,39 & $0,34 \mathrm{q}$ \\
$\mathbf{3 0}$ ton/ha (V2) & 0,34 & 0,36 & 0,42 & $0,37 \mathrm{r}$ \\
\hline Rerata & $0,30 \mathrm{a}$ & $0,34 \mathrm{~b}$ & $0,39 \mathrm{c}$ & $(-)$ \\
\hline
\end{tabular}

Keterangan: Angka-angka yang diikuti huruf yang sama pada kolom $(\mathrm{a}, \mathrm{b}, \mathrm{c})$ atau baris $(\mathrm{p}, \mathrm{q}, \mathrm{r})$ menunjukan tidak ada beda nyata menurut Uji Jarak Berganda Duncan pada jenjang nyata $5 \%,(-)$ : Tidak ada interaksi

Hasil analisis data menunjukkan bahwa pemberian pupuk kandang sapi dan tanah Vertisol sebagai pembenah tanah berpengaruh nyata terhadap peningkatan kadar C-organik tanah. Hasil analisis data juga menunjukkan kadar C-organik tanah tertinggi terdapat pada perlakuan pupuk kandang sapi dosis 30 ton/ha (P2) dengan kadar Corganik sebesar $0,39 \%$, seperti yang dapat dilihat pada tabel 4 . Hal ini sejalan dengan penelitian Partoyo (2005) bahwa penambahan pupuk kandang sapi dapat meningkatkan kadar C-organik tanah, meskipun masih termasuk dalam harkat yang sangat rendah, penambahan pupuk kandang seara nyata lebih tinggi dibanding tanah asli tanpa perlakuan.

Selain itu, pupuk kandang sapi yang digunakan pada penelitian ini memiliki kadar C-organik sangat tinggi dengan nilai 7,8\%, sehingga dengan penambahan pupuk kandang sapi ini dapat meningkatkan kadar C-organik pada tanah pasir pantai. Menurut Hanafiah (2005), penambahan bahan organik dalam tanah akan menyebabkan aktivitas dan populasi mikrobiologi dalam tanah meningkat, terutama yang berkaitan dengan aktivitas dekomposisi dan mineralisasi bahan organik. Semakin banyak penambahan bahan organik pada tanah, maka penigkatan C-organik dalam tanah akan semakin besar.

Peningkatan kadar C-Organik tanah akibat perlakuan tanah Vertisol diduga karena adanya sumber bahan organik pada tanah Vertisol. Hasil analisis pendahuluan juga menunjukkan kadar C-organik pada tanah vertisol sebesar 1,97\%, sehingga dengan adanya penambahan Tanah Vertisol pada tanah pasir pantai mengakibatkan adanya 
peningkatan kadar C-organik tanah setelah perlakuan. Selain itu, kandungan lempung yang terdapat pada tanah Vertisol juga dapat mempertahankan bahan organik tanah pada saat pelindian.

\section{KESIMPULAN}

Pemberian bahan organik dan pupuk kandang sapi dan tanah Vertisol sebagai pembenah tanah memberikan pengaruh nyata terhadap peningkatan ketersediaan Kalium (K) dan penurunan jumlah pelindian Kalium (K) pada tanah Regosol pasir pantai, selain itu penggunaan pupuk kandang sapi dan tanah Vertisol juga berpengaruh nyata terhadap perubahan nilai $\mathrm{pH}$ tanah, dan peningkatan nilai C-organik, dan Kapasitas Pertukaran Kation (KPK) tanah.

\section{DAFTAR PUSTAKA}

Hanafiah, K., A. 2005. Dasar-Dasar Ilmu Tanah. PT. Raja Grafindo Persada. Jakarta. 358 hal.

LPT. 1979. Penuntun Analisa Fisika Tanah. Lembaga Penelitian Tanah. Badan Litbang Pertanian.

Margolang, R., D., Jamilah, dan M Sembiring. 2015. Karakteristik beberapa sifat fisik, kimia, dan biologi tanah pada sistem pertanian organik. Jurnal Agroekoteknologi. 3 (2): 717-723.

Nursyamsi, Dedi dan Suprihati. 2005. Sifat- Sifat Kimia dan Mineralogi Tanah serta Kaitanya dengan Kebutuhan Pupuk untuk Padi (Oryza sativa), Jagung (Zae mays), dan Kedelai (Glycine max). Bul.Agron. 33(3). 40 hal.

Partoyo, 2005. Analisis Kualitas Tanah Pertanian Di Lahan Pasir Pantai Samas Yogyakarta. Jurnal Ilmu Pertanian Vol.12 No.2. 2005:140-151

Prasetyo, B. H. 2005. Mineral Tanah. Bogor: Balai Penelitian Tanah. 39-46hal.

Rajiman, Yudono, P., Sulistyaningsih, E. dan Hanudin, E., 2008. Pengaruh Pembenah Tanah Terhadap Sifat Fisika Dan Hasil Bawang Merah Pada Lahan Pasir Pantai Bugel. Jurnal Agrin 12 (1): 67-77.

Wigati, E.S., A. Syukur, dan D.K. Bambang. 2006. Pengaruh takaran bahanorganik dan tingkat kelengasan tanah terhadap serapan fosfor oleh kacang tunggak di tanah pasir pantai. Jurnal Ilmu Tanah dan Lingkungan, 6 (2): 52-58. 